\title{
EVOLUTIONARY EXPLANATIONS OF EMOTIONS
}

\author{
Randolph M. Nesse \\ The University of Michigan
}

Emotions can be explained as specialized states, shaped by natural selection, that increase fitness in specific situations. The physiological, psychological, and behavioral characteristics of a specific emotion can be analyzed as possible design features that increase the ability to cope with the threats and opportunities present in the corresponding situation. This approach to understanding the evolutionary functions of emotions is illustrated by the correspondence between (a) the subtypes of fear and the different kinds of threat; (b) the attributes of happiness and sadness and the changes that would be advantageous in propitious and unpropitious situations; and (c) the social emotions and the adaptive challenges of reciprocity relationships. In addition to addressing a core theoretical problem shared by evolutionary and cognitive psychology, explicit formulations of the evolutionary functions of specific emotions are of practical importance for understanding and treating emotional disorders.

KEY WORDS: Adaptation; Anxiety; Evolution; Fear; Feelings; Emotion; Mental disorders; Mood; Natural selection; Psychiatry; Psychology; Reciprocity; Relationships

Received November 22, 1989; accepted December 15, 1989.

Address all correspondence to Randolph M. Nesse, M.D., Department of Psychiatry, The University of Michigan Medical Center, Med-Inn Building, Room C440, Ann Arbor, MI48109-0840.

Copyright () 1990 by Walter de Gruyter, Inc. New York

Human Nature, Vol. 1, No.3, pp. 261-289.

$1045-6767 / 90 / \$ 1.00+.10$ 


\section{THE PROBLEM}

Why do we have the capacities for love, anger, fear, happiness, and sadness? Although this ancient question has not yet yielded to scientific methods, there is increasing agreement that any answer must be based on an understanding of how natural selection has shaped the capacities for the emotions. Exactly how to reach this understanding remains, however, an open question. My thesis is that our understanding of the emotions will increase most rapidly not by only asking how they work, but by also asking what functions they serve. These questions about function can best be answered by formulating and testing explicit evolutionary explanations for specific emotions.

\section{The Utility of a Theory of Emotions}

Understanding the emotions is of both practical and theoretical importance. Psychiatrists and other clinicians who treat emotional disorders base their work on some theory of emotions, whether explicit or implicit. It is painful emotions, after all, that usually motivate psychological treatment. The most common psychological problems, depression and intense anxiety, are extreme versions of normal sadness and fear. The clinician's first task is to decide if a patient's emotions are normal, or if they are manifestations of an emotional disorder. One might reasonably expect these decisions to be based on a solid theory of normal emotions and their functions, but this is not the case. No theory of emotions is widely accepted, and existing knowledge about emotions has been transmitted to few clinicians. A sturdy theory of the functions of emotions, even if crude, would have enormous clinical utility.

The policies that should regulate the use of psychotropic drugs are the topic of a widening debate (Nadelmann 1989), but our theories of emotions are not powerful enough to help much. When should we use drugs to help people to feel better, and when should we not? Which substances should be legal and which should not? Are drugs that induce pleasure categorically different from those that relieve pain? Coherent answers to these questions await a better understanding of the origins and normal functions of the emotions.

Understanding the adaptive significance of the emotions is also crucial to both cognitive and evolutionary psychology. Emotional states not only motivate action, they are also goals that we seek to achieve. Most human thought, plans, and actions are intended to induce positive emotions or to avoid negative emotions. Such actions tend, as a result of mechanisms that we only vaguely comprehend, to increase Darwinian 
fitness. Attempts to improve our understanding of the connection between emotions and adaptive behavior may provide a focus for synergistic efforts by cognitive and evolutionary psychology. Emotions may be paradigmatic "specialized, domain-specific Darwinian algorithms" of the mind (Cosmides and Tooby 1989:60).

\section{Difficulties with Current Theories of Emotions}

After concluding, some years ago, that a better understanding of what was known about the emotions would be useful on several counts, I undertook to remedy this gap in my education. Enthusiasm gave way to frustration-a reaction that was, it soon became clear, widely shared. Many articles about emotions begin by deploring the state of emotions theory, noting the lack of agreement even about what emotions are, to say nothing of what they are for. The following lament written by William James in 1880 seems to have struck a particularly responsive chord throughout the past century:

\footnotetext{
But as far as the "scientific psychology" of the emotions goes, I may have been surfeited by too much reading of classic works on the subject, but I should as lief read verbal descriptions of the shapes of the rocks on a New Hampshire farm as toil through them again. They give one nowhere a central point of view, or a deduction or general prindple. They distinguish and refine and specify in infinitum, without ever getting on to another logical level (1962:377).
}

More than 100 years later, each theorist still starts afresh. Agreement remains elusive even about basic issues. What are the emotions? Plutchik (1980) lists 27 different definitions. How many basic emotions are there? Each theorist has a different list. Does each emotion have an opposite? Some say yes; others, no. Which aspect of emotions is primary? Some say physiology; others, cognition; others, behavior; and some say no single aspect is primary. Why do emotions all have hedonic valence? There is disagreement. And finally, what functions do the emotions serve? Some authors emphasize motivation; others, communication; and still others, cognition. There is no consensus on the answers to these major questions about the emotions.

\section{Converging Approaches}

Despite the lack of full agreement on any single issue, OpInIOn is converging in several areas. Most important of all is agreement with the 
view that emotions are legitimate objects of scientific inquiry. At the height of behaviorism, even this view was questioned. The return of emotion to the legitimate status it occupied in nineteenth-century psychology is likely "due to the current vitality of evolutionary biology and neurophysiology" (Izard et al. 1984:1).

The general disregard for emotions in: the mid-twentieth century combined with the dominance of behaviorism and rationalism to support the extreme conclusion that the whole concept of emotion was useless-emotions were mere disruptions of normal functioning (Duffy 1941). A turning point in this debate was a 1948 paper by Leeper that argues for the utility of emotions as motivators. Although emotions can, like other traits, be maladaptive in excess or in the wrong circumstances, their general utility is now accepted. This conclusion, in concert with the recognition that emotions are products of brains shaped by natural selection, has led many researchers to advocate consideration of the evolutionary origins and functions of the emotions, including Ekman (1982), Emde and Goensbauer (1981), Hamburg (1968), Hinde (1972), Konner (1982), Ohman (1987), Panksepp (1982), Plutchik (1980), and Scott (1980). Ethological approaches to the emotions have been offered by Eibl-Eibesfeldt (1980), Gilbert (1989), and Scott (1980). Gaylin (1979) has engaged the interest of a general audience in the utility of emotions.

Agreement with the concept that emotions are best viewed as systems of coordinated changes in physiology, cognition, and behavior is also evident. Although many theories still emphasize one aspect at the expense of others, few now argue that one is primary. A view of emotions as coordinated systems has been strongly advanced by Arnold (1960), Izard (1977), Lazarus et al. (1980), Plutchik (1980), Strongman (1987), Tomkins (1980), and Young (1979). Somewhat surprisingly, in his 1872 book on emotions Darwin did not recognize the multiple functions of the various aspects of emotion; instead he emphasized only communication. The emotions were, he thought, transmitted by Lamarkian inheritance (Darwin 1965).

It has been recognized for some time that each emotion is useful only in certain situations. This fact is so basic and so widely recognized that its importance is easily overlooked. Because each emotion is aroused only in specific kinds of situations, its functions will make sense only after a detailed consideration of the characteristics of those situations.

The growing consensus on these issues supports my initial premise that emotions are coordinated systems of response that were shaped by natural selection because they increased fitness in certain situations. Reviews that generally support this position can be found in Plutchik and Kellerman (1980). 


\section{EVOLUTIONARY EXPLANATIONS OF EMOTIONS}

All biological phenomena require two separate kinds of explanation, proximate and evolutionary. The proximate explanation accounts for the structure of a biological character, its ontogeny, and how it works. The evolutionary explanation accounts for the function of the character, its evolutionary history, and why it exists at all (Mayr 1988). If, for instance, we understood every detail of the bat's sonar apparatus, from neuronal transmission to anatomy and sound generation, this understanding would provide a complete proximate explanation, but we would still need an evolutionary explanation of the functions of the apparatus and how it was shaped by natural selection. Alternatively, if we knew the exact adaptive significance of the firefly's glow, we would still need a proximate explanation of the structure, regulation, and ontogeny of the glow organ.

The necessity for both proximate and evolutionary explanations is well accepted in biology, but it still elicits raised eyebrows elsewhere. Uneasiness about using the concept of function as a part of explanations seems to be at the root of the difficulty. This uneasiness results, in part, because arguments about function confused the physical sciences and now are deservedly excluded from consideration. But biology is different from the physical sciences precisely because the traits of living organisms have been shaped to serve functions that increase fitness. Additional uneasiness results from the difficulty of formulating and testing hypotheses about function, and the tendency, deplorable but common, to assume the truth of any plausible hypothesis about a trait's function. Tinbergen's (1963) well-known four questions provide an excellent framework for organizing the different parts of a complete explanation of an emotion (Table 1). Answers to the first two provide a proximate explanation, whereas answers to the second two provide an evolutionary explanation. A crucial task is to decide how best to formulate answers to the third question as it applies to emotions, so they can be explained in the same way as other biological traits.

Still another problem arises because it is easy to assume wrongly that a functional trait must be a product of a plan or design. But turtles have shells that protect them from predators only because turtles that had shells survived and reproduced better than those that did not. The process that created the shell, natural selection, has no plans, no goals, no direction, and does not create perfection. It is just the inevitable tendency for the frequency of genes that tend to result in phenotypes that tend to have more offspring to increase, and the converse tendency for the frequency of genes that tend to result in phenotypes that tend to 
Table 1. An Outline for an Evolutionary Explanation of an Emotion

I. Proximate explanation of the physiological and psychological mechanisms that mediate and regulate the emotion
A. Cues that elicit the emotion
B. Mechanisms that assess the cues and regulate the emotion
C. Characteristics of the emotional state
1. Physiological characteristics
2. Behavioral characteristics
3. Cognitive/subjective characteristics

II. Ontogeny of the proximate mechanisms

III. Evolutionary explanation of how the emotional capacity was shaped by natural selection-its functions that increase(d) fitness

A. The situation in which the emotion is adaptive

1. Associated threats

2. Associated opportunities

B. Adaptive significance of aspects of the emotion

1. Physiology (especially of its arousal, but also of more specialized patterns)

2. Behavioral tendencies and patterns (especially facial expressions)

3. Cognitions and subjective changes (especially motivation, planning)

4. Other aspects of the emotion, including sensory changes

IV. Phylogeny of the emotional capacity

have fewer offspring to decrease (Williams 1966). Despite the uncertainty at each step, biological characters are shaped to serve their functions effectively.

\section{What Traits Have Evolutionary Explanations?}

How can we distinguish between traits that have and traits that have not been shaped by natural selection? The best evidence for a trait having been shaped by natural selection is often an argument from design-that is, a demonstration of how the subtle details of the trait work together to serve a particular function. More basic criteria can, however, eliminate certain kinds of traits from consideration to save wasted effort and to forestall the creation of attractive, but impossible, adaptive stories. 
Some traits that vary substantially within a species are unlikely to be of adaptive significance (e.g., hair color), or they serve functions that offer benefits only to populations that live in certain locations (e.g., sickle-cell protection against malaria). We will bypass the complexities of these types of inherited individual differences and will limit consideration to those aspects of human nature that we all have in common.

Some traits that are uniform in a species are poor objects of evolutionary explanation because they (a) never served an evolutionary function, (b) no longer serve a function, (c) are components of an adaptation that is best analyzed at another level, (d) are manifestations of phylogenetic constraints, or (e) result from fixation of mutations by genetic drift. The color of blood could not, itself, have been acted on by natural selection; it is a happenstance outcome of a hemoglobin molecule shaped for its ability to bind oxygen. The tendency of hair to stand on end during terror is an atavistic remnant of a trait that probably no longer provides a selective advantage. The wrinkles of skin over the knuckles are best analyzed as components of the finger joints. And the presence of only 10 fingers instead of the 20 that might be more adaptive for typing is an example of a phylogenetic constraint. Finally, mutation and genetic drift may result in fixation of some simple, adaptively insignificant traits, although they cannot account for traits that have complex organization or substantial adaptive significance (Dawkins 1982: 32-33).

These important caveats should not distract from the central principle that complex biological traits must have been shaped by natural selection. And traits are shaped by natural selection only if they serve some function that increases Darwinian fitness. Fitness, in this sense, means inclusive reproductive success. Health and survival mean nothing to Darwinian fitness, except insofar as they increase reproduction of the individual or the individual's kin.

Are the capacities for emotions legitimate objects of evolutionary explanation? They are certainly products of a brain shaped by natural selection. But might they be epiphenomena of other processes, without adaptive significance themselves? This suggestion seems unlikely for several reasons: emotions are complex, they are traits shared to some degree by all people, and they are important to fitness. People who lack normal emotions, and people whose emotions are disrupted by substance abuse, are, as psychiatrists know only too well, profoundly disabled. It appears likely, even before we assess the fit between the characteristics of emotions and the adaptive challenges they meet, that the emotions have been shaped by natural selection and that we are therefore justified in trying to discover the functions they have served. 


\section{Functions of Basic Emotions}

The benefits of emotions have long been considered to arise from three broad categories of functions: motivation, communication, and cognition. These categories were recognized long before Darwin, but a modern systems approach has decreased the tendency to emphasize one function at the expense of others. This view represents a major advance, but application of these categories cannot explain how different emotions make different contributions to fitness. To proceed, we need a framework that facilitates analysis of the adaptive significance of each detail of each different emotion by specifying the selective forces that have shaped them.

\section{WHAT ARE THE EMOTIONS?}

The provision by each theorist of a different definition of emotions is not as problematic as it may seem, since at present the main task of emotions research is still to conceptualize emotions in a coherent way. Biological systems are usually defined in terms of their functions. For instance, the immune, circulatory, and gastrointestinal systems are defined, respectively, by their functions of protecting against infection, circulating bodily fluids, and breaking down and absorbing nutrients. The emotions must also be defined in terms of their functions. Agreement on the definition of emotions will remain elusive until there is agreement on how best to conceptualize their functions. The following proposed definition of emotions is based on my approach to understanding their evolutionary functions.

The emotions are specialized modes of operation shaped by natural selection to adjust the physiological, psychological, and behavioral parameters of the organism in ways that increase its capacity and tendency to respond adaptively to the threats and opportunities characteristic of specific kinds of situations. This formulation predicts that each emotion should correspond to a particular kind of adaptively significant situation that has occurred repeatedly in the course of evolution, and that the detailed characteristics of an emotional state can be analyzed as design features that increase the individual's ability to cope with the particular kinds of adaptive challenges that arise in this situation.

These adaptive challenges are the selective forces that shaped the content and the regulatory mechanisms of each emotion. An evolutionary explanation of an emotion must, therefore, be based on a description of these challenges. This emphasis on the correspondence between a specific emotion and a specific situation is the central feature of my 
formulation. It has always been recognized that certain kinds of situations arouse certain emotions, but my thesis is that the adaptive challenges of certain situations have, by natural selection, shaped the various emotions. The definition of a specific emotion, and an understanding of its adaptive significance, must be sought in the intricate relationship between the components of the emotion and the situation that shaped it.

A number of evolutionary approaches have paired emotions with various adaptively significant categories: problems of adaptation (Plutchik 1980), behavioral systems (Scott 1980), biosocial goals (Gilbert 1989), and action impulses (Lazarus et a1. 1980). Lyons (1980) concludes, from philosophical analysis, that understanding the eliciting situation is the key to understanding an emotion. My proposal is in fundamental agreement with each of these authors. It differs mainly in attempting to specify more exactly the situations and selective forces that have shaped each emotion.

Software of the Mind?

In several respects, emotions provide for the mind what software programs provide for the computer. A computer is ineffective until software programs are loaded to adjust its various parameters to the needs of a particular task. Loading a program changes the appearance of the screen, the functions of certain keys, the use of certain processing chips, and access to certain kinds of information. Similarly, an emotion may change the expression on the face, the response to particular stimuli, the tendency to use one or another kind of thinking, and the availability of certain memories.

This analogy is, however, limited in several ways. Programs are loaded into random access memory, but emotions are more like programs that are wired on a chip. Different programs correspond to specific tasks, but different emotions correspond to specific kinds of adaptively significant situations. Programs are shaped from scratch by purposeful people, but emotions are shaped from available precursors by the statistical process of natural selection. Finally, different emotions can be aroused to different degrees all at once, but programs are generally either loaded completely into the computer or not at all, and they are most often used one at a time. Despite these limitations, the analogy helps to clarify the nature of emotions as specialized modes of operation in which a variety of organismic changes increase the ability to cope with the adaptive challenges of different situations. 


\section{The Basic Emotions}

There are as many lists of basic emotions as there are emotions theorists, but here again, the disagreement is not as problematic as it may seem. The objectively derived lists of Plutchik (1980) and Schwartz et al. (1987) mainly confirm the intuitions of their predecessors. Almost all the lists include the same core emotions: fear, anger, happiness, sadness, and love. If my formulation is correct, then each of these basic emotions should correspond to a situation in which a specialized state of operation can augment fitness. Ways in which this hypothesis can be tested are illustrated by considering several basic emotions.

\section{FEAR}

If different emotions correspond to different kinds of situations, different subtypes of fear may have been shaped to deal with several kinds of threats. Many subtypes of fear are well recognized. Different kinds of fear are aroused by predators, high places, threatening strangers, hostile relatives, crucial social situations, diseases, and illicit wishes. Susceptibility to fear is clearly not a single trait; each subtype is regulated somewhat separately. For instance, people who have a social phobia may not be afraid of snakes, but they may be terrified by being the center of critical attention.

How well do the subtypes of fear match the different kinds of threats? We have no taxonomy of normal fears, but the syndromes of pathological fear recognized by psychiatrists (American Psychiatric Association 1987; Marks 1987) offer an approximation, provided one accepts the plausible assumption that these syndromes represent exaggerations of normal patterns of fear. As Table 2 shows, the match between different threats and different subtypes of fear is remarkably good.

\section{Panic and Agoraphobia}

Not only do the subtypes of fear correspond to the threats humans face, but many details of these subtypes can be analyzed as design features that protect against particular threats. For instance, imminent danger of attack elicits panic, a coordinated pattern of physiological, psychological, and behavioral alterations. The adaptive significance of the physiological changes that accompany panic were astutely recognized by Cannon (1929:193-224): increased sugar in the blood is available for metabolism; epinephrine reverses fatigue; the nervous system 
Table 2. Subtypes of Fear and Their Corresponding Situations

\begin{tabular}{ll}
\hline Subtype of Fear & \multicolumn{1}{c}{ Corresponding Danger or Situation } \\
\hline Panic & Imminent attack by predator or human \\
Agoraphobia & Environment in which attack is likely \\
General anxiety & Environment that is unsafe in general \\
Conflictual anxiety & Socially unacceptable impulses \\
Social anxiety & Threats to status or group membership \\
Small animal phobias & Dangerous small animals \\
Hypochondriasis & Disease \\
Separation anxiety & Separation from protective parent \\
Stranger anxiety & Likelihood of harm from strange humans \\
Personal inadequacy & Rejection by allies or group \\
Obsessive cleanliness & Infectious disease \\
Obsessive hoarding & Lack of food or other resources \\
Blood/injury & Wound \\
\hline
\end{tabular}

re-routes blood circulation to support maximal exertion; increased muscle strength and tension facilitate action; higher concentration of blood corpuscles and rates of respiration increase exchanges of oxygen and carbon dioxide; and increased blood coagulability prevents excessive blood loss.

Panic alters cognition and behavior as well as physiology. The mind becomes focused on finding escape routes. If none are obvious, anxiety rises quickly. Motivation to flee towards home and trusted relatives becomes overwhelming (Marks 1987). Facial and vocal expressions of fear solicit aid and warn kin of danger. The state of panic is a coordinated syndrome whose components occur together, not because they arise from a neuroanatomic locus, but because they are useful in the face of imminent attack.

The cues that most often elicit panic are those associated with increased risk of attack (Lelliott et al. 1989). People who repeatedly experience panic develop agoraphobia, a remarkably consistent syndrome that includes fears of specific cues: wide open spaces, closed in spaces, places where intense fear has occurred before, and being far from home, especially if unaccompanied by a trusted relative. These characteristic agoraphobic fears are well suited to avoiding attack in a dangerous environment (Nesse 1988). A person who lacks the tendencies to panic in the face of danger and to experience agoraphobic fears in dangerous situations will, in a natural environment, be at a selective disadvantage. Panic disorder is a disease that results from faulty regulation of panic, but panic itself, like cough, is not a disease, but a defense against a particular kind of danger. 


\section{Other Kinds of Fear}

The snake phobic experiences physiological arousal nearly identical to that which occurs in panic, but the associated motivation is differentnot to flee towards home and relatives-but to get away from the snake. Though rarely a threat in modern societies, snake bites were a selective force in past generations, as is indicated by the ready conditioning of fear responses to snake stimuli and the relative difficulty of extinguishing such responses (Mineka et al. 1980; Ohman et al. 1985).

Being the center of social attention seems harmless enough, until it is recognized that human competitions are mainly social competitions (Alexander 1989). Ridicule and social failure are not just discomforting, they are serious threats to reproductive success. The fear of success, often thought to typify maladaptive neurosis, must sometimes be adaptive if leaders exclude or punish those who threaten their positions (Hartung 1988).

Children have special kinds of anxiety that emerge and fade in synchrony with the kinds of dangers they are likely to face. Protest caused by separation from mother is among the earliest of social emotions, arising at about the age when the infant first crawls. Bowlby (1973) and Harlow and Zimmerman (1959) have convincingly argued for the evolutionary utility of these fears. Fear of strangers seems less useful, until it is recognized that strangers, even those within the same group/ pose serious threats to infants (Marks 1987:19-24).

\section{MOOD}

Happiness and sadness are, along with fear, the most basic emotions. My goal here is not to propose a full explanation of mood, but only to argue that the capacity for ordinary happiness and sadness requires an evolutionary explanation, and that this explanation must be based on a changeable and evolutionarily important aspect of the environment. The evolutionary functions of mood are the object of increasing research. Gardner (1982)/ Gilbert (1989)/ and Price and Sloman (1987) have especially emphasized the role of social hierarchy in regulating mood, whereas Thayer (1989) has emphasized the adaptive significance of mood and arousal in response to diverse everyday events, and McGuire and Troisi (1987) have emphasized the regulatory functions of mood.

There are several reasons to think that happiness and sadness have been shaped by natural selection. They are universal human experiences 
with coordinated cognitive, physiological, and behavioral aspects; they are important to fitness; and they are regulated by cues that correlate with changes in fitness. Happiness is aroused by information that is often correlated with increasing reproductive success-being admired, being loved, making love, having children, watching them succeed, and having grandchildren. Sadness is aroused by situations associated with decreasing fitness-sickness, loss of status, loss of resources, social rejection, loss of a friend or lover, or death of a child.

Happiness and sadness seem to be tracking some environmental variable, but what is it? Can it be fitness itself? We probably have definite preferences for and against situations associated with higher and lower fitness, however, it seems unlikely that we have mental machinery that adjusts current behavior to maximize the number of grandchildren.

An immediate and important function of mood is as a motivator. People repeat actions that made them feel happy in the past, and they avoid actions that made them sad. On a higher cognitive level, people plan their actions based on their expectations of the emotional states that will result. But this function of mood is useful mainly for understanding the relatively brief and simple kinds of happiness and sadness that could be called mental pleasure and pain. It cannot fully explain more enduring states of happiness and sadness and their many details.

Consideration of the characteristics of states of high and low mood gives clues to the kinds of situations in which they offer advantages. The happy person is energetic, optimistic, assertive, socially outgoing, eager to start new projects, and makes substantial investments in people and projects with confidence that they will payoff. The sad person is lethargic, pessimistic, submissive, socially withdrawn, excessively realistic about personal abilities, and has little initiative for new relationships or projects. The situations in which these characteristics would seem to increase fitness are not characterized by recent success or failure, but by indicators of future rewards per unit investment. Is the propitiousness of the current environment, that is, the ratio of available rewards per unit investment, the variable to which high and low mood correspond? It certainly would be useful for an organism to regulate its energy and social investments to make them when they will payoff especially well, instead of at times when they will be wasted. In addition, the strong influence of social events on mood matches the importance of regulating social investments. The situations in which high and low moods offer advantages mayor may not eventually be best characterized as propitious and unpropitious, but they almost certainly correspond to some important environmental variable-one that must be specified before we can say we understand mood. 


\section{THE SOCIAL EMOTIONS}

Darwinian success for humans depends substantially on social success, and social success depends substantially on successful negotiation of reciprocity relationships (Alexander 1989; Barkow 1980; Wenegrat 1990). If my main hypothesis is correct, then the categories of adaptive challenges that arise in the course of reciprocity relationships should each have shaped specialized emotional states whose characteristics increase the ability to cope with these challenges.

\section{Reciprocity Theory}

People interact with other people for two main reasons. First, genes that increase the tendency to help kin (who share some of those same genes) will tend to increase in frequency in the gene pool if the help is less expensive to the giver than the benefit to the receiver, times the proportion of genes shared in common. This is William Hamilton's (1964) central insight into how kin selection can explain the evolution of helping behavior that is otherwise difficult to understand. It has done away with most explanations based on group selection, and it has revolutionized the study of animal behavior.

Relationships with nonrelatives require a different explanation, one that was formulated especially well by Robert Trivers (1971) as reciprocal altruism theory. Many tasks are more efficiently accomplished by cooperation. The advantages of specialization and pooling of labor lead to exchanges different in kind or delayed in time. This situation results in both advantages from reciprocity relationships and opportunities for cheating and defection that seem to be taken advantage of by all social species.

The "prisoner's dilemma" (Table 3) is often used as a model for patterns of reciprocity exchange. The name comes from the situation in which two criminals are interrogated separately. The police advise each of them that a confession will result in freedom for the person who provides it first (the "defector"), and a harsh punishment for the other

Table 3. A Prisoner's Dilemma Model for Reciprocity Relationships

\begin{tabular}{lccc}
\hline & $\begin{array}{c}\text { (OTHER) } \\
\text { Cooperate }\end{array}$ & $\begin{array}{c}\text { (OTHER) } \\
\text { Defect }\end{array}$ \\
\hline$[$ SELF] & Cooperate & {$[2](2)$} & {$[0](3)$} \\
{$[$ SELF] } & Defect & {$[3](0)$} & {$[1](1)$} \\
\hline
\end{tabular}


Table 4. Emotions That Mediate Reciprocity Relationships

\begin{tabular}{cccc}
\hline & & (OTHER) & (OTHER) \\
& & Cooperate & Defect \\
\hline$[$ SELF] & Cooperate & Friendship, Love & (Anxiety, Guilt) \\
& & Obligation, Pride & [Anger] \\
{$[$ SELF] } & Defect & (Anger) & Rejection \\
& & [Anxiety, Guilt] & Hatred \\
\hline
\end{tabular}

person. If neither confesses ("cooperates"), both receive a mild punishment, but if both confess, both get an intermediate sentence. If the decision is made only once, the best general strategy is to confess ("defect") before the other person does. If the game is played repeatedly, with the number of points awarded to the "self" and "other" depending on the actions taken in each turn (see Table 3), constant cooperation yields the maximum total long-term return for both players, but in every turn of the game the temptation exists to defect and thereby gain a relative advantage.

The ideal strategy in a prisoner's dilemma game without a fixed endpoint is remarkably simple. This strategy, usually called "tit-for-tat," is to cooperate on the first move of the game, and then to do whatever the other person did on the last move (Axelrod and Hamilton 1981). Thus, one takes maximum advantage of opportunities to cooperate without opening oneself to exploitation if the other person defects.

To the extent that this model accurately represents common patterns of human interactions, we should find emotions that correspond to each cell in the diagram, since each constitutes an adaptive challenge that has repeatedly confronted humans, and to which an appropriate response is essential to fitness. This approach, presented in Table 4, was suggested by Trivers's (1981) comments on the functions of the social emotions and by Cosmides and Tooby's (1989) studies of the psychology of social exchange.

Friendship, Love, Pride, and Obligation

We will start with the familiar situation in which both parties cooperate. Repeated exchanges of assistance arouse feelings of trust and liking. These feelings have obvious utility because they motivate continuation of a mutually profitable relationship, but friendship and love go much deeper. These emotions are aroused not by mere reciprocity exchanges, but by situations in which help is provided without explicit 
requirements for reciprocity. Evolutionary studies of attachment have been based on the functions of infantile attachment (Ainsworth et al. 1978; Bowlby 1973; Harlow 1959), with only a few exceptions (Smuts 1985). However, adult relationships based on emotional attachments increase vulnerability to exploitation and would seem to be disadvantageous.

Why are adult relationships not all based on simple straightforward reciprocity exchange? What special advantages are offered by the capacity for basing relationships on intense and enduring emotional attachments? Two parties who can count on extended reciprocity exchanges that transcend opportunities for short-term gain by cheating or defection will have an advantage over individuals who cannot establish this type of relationship. Emotions that mediate such commitments, and motivate behaviors that are altruistic in the short run, can therefore be shaped by natural selection. A person with an "irrational" willingness to help a friend may have an advantage over a person who abandons relationships when they appear to have outlived their usefulness. The benefits of these emotional tendencies may be described in terms of their ability to help to solve the "commitment problem," as it is described in economic theory (Frank 1988).

It has been proposed that aggressive interactions between potential relationship partners may be explained as "testing of a bond" (Zahavi 1976). This suggestion makes sense if individuals are vulnerable to exploitation by those who simulate emotional attachments. Aggressive and defecting behavior provide short-term costs that weed out those who lack emotional commitment. Lovers' spats may be essential and adaptive tests of the partner's reliability and sincerity.

Some of the cynical tone that characterizes evolutionary psychology results, it seems to me, from our lack of knowledge about how the capacities for attachment, anxiety, and guilt offer selective advantages. The revelation that all evolved human behavioral characteristics must ultimately serve the interests of "selfish genes" has extended to the view that friendship and guilt must somehow be "selfish." They must offer advantages to the individual in the long run, but they are "altruistic" in the ordinary meaning of the word-they motivate behavior that benefits others with no obvious immediate benefit in return. The very "irrationality" of emotional attachment may be crucial to its adaptive functions.

Reciprocity exchanges are rarely in exact balance. If one individual has provided more than the other, the emotions of pride and entitlement arise. The pride that results from performing one's duty gives moral satisfaction and, often, a sense of moral superiority. The tendency for people who have helped others to feel "entitled" to help in return is a 
useful check on unfair exchanges. Persistent feelings of entitlement are, however, a core problem in much modern psychopathology and are usually thought to result from defects in the early mother--child relationship. An evolutionary view supports this possibility and suggests that early patterns of mother--child exchange may be of special importance in the development of narcissistic personality disorders.

If, in a social exchange, the other person has provided more than oneself, humiliation and obligation arise. These emotions increase efforts to balance the exchange. When the imbalance becomes extreme, increasing rewards for defection make the relationship unstable. Consistent and fair exchanges make for stable and secure relationships.

\section{Anger}

When the other person defects by not providing help in return, or cheats by doing less than is fair, anger is the usual response. Anger includes not only threats to abandon the relationship, but also spiteful threats to harm the other person, often at great cost to the self. Anger is not a reasoned negotiating ploy; it is an agitated, irrational, unpredictable state of aggressive arousal.

How can anger possibly be adaptive? Why not just ignore the person who will not cooperate and look instead for a different reciprocity partner? The answer may be that anger is worthwhile precisely because relationships are valuable. Anger signals that a defection or potential defection has been detected and will not be tolerated. Its most basic function is to protect against exploitation. But by increasing the cost to a potential defector, the threat of spiteful retaliation also, paradoxically, helps to preserve relationships. This helps to explain why the angry person is unpredictable and irrational. If anger is to be effective, the target of the anger must believe that the angry person may act in ways that have substantial costs, and the reality of this threat can be maintained only if the anger does sometimes motivate irrational attacks. This same principle protects the small person who defies a more powerful bully. It may seem senseless to fight a stronger opponent when the chances of winning are poor, but the threat of such irrational behavior may deter attack and exploitation.

\section{Anxiety}

It is not always the other who is tempted to defect-we all fail to fulfill small and large obligations. Should one stay late and finish the report promised to the boss, or go home for dinner as promised to the spouse? 
Should one marry the old sweetheart, as promised, or pursue the new potential spouse who seems preferable? These are the dilemmas of life. When we are tempted not to fulfill a personal or moral expectation, we experience anxiety, a special kind of fear that is aroused by inner impulses that may, if acted on, bring social dangers.

One adaptive function for anxiety is readily recognized-it motivates cooperation when it is inconvenient or seemingly not in our best interests. Once again, the special value of relationships resolves an apparent paradox. Internal motives that advocate our long-term interests are essential to oppose motives that advocate more immediate gratification (Nesse and Lloyd 1990). The characteristics of anxiety fit this adaptive challenge. The anxious person ruminates about the obligation, is distracted from more immediate sources of gratification, becomes vividly aware of the costs of noncooperation, and has difficulty resting calmly until the tension is resolved. If the anxiety prevails, the foregone alternative gratification is depreciated ("sour grapes") or repressed (Nesse 1990) and pride arises in its place. If individual gratification prevails, either the obligation is depreciated, or guilt arises and motivates new attempts to help the other person.

\section{Guilt and Self-punishment}

Guilt and self-flagellation also serve important functions. To restore a relationship after a defection, something more than simple reparations are necessary. Reparations can reestablish the balance in a relationship, but mere repayment implies that the relationship is based only on reciprocity, not on friendship that can be relied on when reciprocation will be difficult or uncertain. People with the capacity to experience deep commitments to each other's welfare have a major advantage over those who merely engage in exchanges when the outlook is favorable for reciprocal return. People capable of commitment will be uninterested in most relationships based only on reciprocity. This statement brings us to a consideration of conscience and its functions. I have argued elsewhere that several selective advantages accrue to people who have a capacity for conscience that securely preserves rules of social conduct and who experience guilt to enforce obedience to those rules even when they seem senseless (Nesse and Lloyd 1990).

\section{OTHER EMOTIONS}

These discussions of several basic emotions have been provided to illustrate a general approach to analyzing the functions of emotions. 
Much more could be said about each one. Many other emotions-envy, jealousy, boredom, curiosity, expectation, surprise, and romantic infatuation, to list only a few-have not been considered. These other emotions no doubt also serve adaptive functions that correspond to the situations in which they are aroused, but a basic problem arises when one attempts to distinguish between basic and secondary emotions. Attempts to designate a sharp boundary between basic and secondary emotions are unjustified, it seems to me, because some situations must be common enough and significant enough to begin to shape specialized states of operation, but not common or significant enough to create a well-defined emotion like fear or anger.

Nonetheless, attempts to understand complex emotions will be valuable. Male sexual jealousy offers a good starting point. It is aroused by the specific situation of a threat to a mate's fidelity, is present in all cultures, and its characteristics seem well suited to discourage potential male competitors and to limit opportunities for the mate to be unfaithful (Daly et al. 1985). A man who has a relatively weak tendency to be jealous is more likely than other men to have his mate become pregnant by someone else, thus decreasing the number of children he will have and increasing the possibility that he will make a major investment in a child who shares none of his genes. Whatever genetic factors contribute to this tendency will spread in the gene pool. The important question, one I cannot answer, is how to determine if the emotion of jealousy has been shaped specifically to increase fitness in this situation, or if it can be sufficiently explained as a combination of more basic emotional tendencies, such as envy, sexual desire, anger, and attachment. Efforts to solve this problem are badly needed.

\section{ARE EMOTIONS INNATE?}

Debates about whether traits result from nature or nurture have, thankfully, become less simplistic as more people realize that all phenotypes represent the outcome of genotypes interacting with environments. It remains important, however, to distinguish aspects of the phenotype that are tightly constrained by genes (e.g., the neural and vocal mechanisms that make speech possible) from those that are determined mainly by individual experience (e.g., what specific language a person speaks).

The nearly universal reports of certain basic emotions suggest that there is wiring in the brain for these patterns, as do experiments that show recognition of facial expressions across cultures (Ekman 1982). Elicitation of specific emotions by stimulating specific brain loci provides 
additional evidence (Panksepp 1982). But reports of cross-cultural variation in patterns of emotions (Lutz 1982) make it equally clear that they are not fixed responses popping out, cuckoolike, from a clockwork mechanism. The characteristics of emotion and the cues that elicit them are different in different cultures and in different individuals. This variability in no way undermines an evolutionary approach. Far more useful than fixed patterns of response are patterns and regulatory mechanisms that adjust to the needs of the current environment (Livesey 1986; Staddon 1983). The mechanisms that make this flexibility possible were shaped, after all, by natural selection.

An excellent illustration is offered by fear. It develops readily in response to heights, darkness, snakes, spiders, and strange angry faces, stimuli that have commonly indicated the presence of danger throughout our evolutionary history (Mineka et al. 1980; Ohman 1987). These fears can, however, be eliminated by behavioral therapy (Marks 1987). It is much harder to condition fear to novel stimuli, even those that indicate modern dangers, such as knives, poisons, guns, and standing on sidewalks with lethal cars speeding by (Ohman et al. 1985), but such fears can be learned. Natural selection has not shaped fixed patterns of response; rather, it has shaped propensities to establish and maintain certain conditioned avoidance reactions, and capacities to adjust these responses to the current environment. This flexibility has costs. Curio (1978) describes a dramatic example in which a blackbird heard an alarm call while watching a harmless honey-eater bird and subsequently developed a fear of honey-eaters that was passed on, successively, through six other blackbirds.

\section{EMOTIONAL DISORDERS}

It is by now abundantly clear that I think much ordinary emotional distress is useful. Before again considering where to draw the line between normal and abnormal emotions, we must first ask why all emotions are either pleasurable or unpleasurable but not neutral. It is because natural selection shapes emotions only for situations that contain threats or opportunities. There are more negative than positive emotions (Averill 1980) because there are more different kinds of threats than opportunities. Negative feelings may be more common and persistant than positive ones because happiness is not the normal state of life, but a goal, a carrot in front of us as we try to relieve our current discomforts and thereby to increase our fitness. As Wilson put it, "Love joins hate; aggression, fear; expansiveness, withdrawal; and so on; in blends designed not to promote the happiness and survival of the indi- 
vidual, but to favor the maximum transmission of the controlling genes" (1975:4).

\section{Bad Feelings for Good Reasons}

We began with the clinician/s dilemma-how to determine if an emotion is normal or not. An evolutionary approach, as it becomes more sophisticated, should prove helpful. Like all advances, however, it also raises new problems. Bad feelings exist for good reasons. Painful states of mind are not abnormalities themselves, they are parts of evolved defensive patterns. If we artificially block these feelings, whether by drugs or psychological manipulations, we may do as much harm as the physician who excessively relieves the useful cough of a patient with pneumonia. An evolutionary perspective compels respect for the value of painful feelings. It forces us to acknowledge that many states we might like to see as disorders are not disorders at all, but potentially useful responses to a threat or a loss.

However, not all mental suffering is useful. Defects in regulatory mechanisms cause much suffering, probably including panic, obsessions/ and major depression-conditions I view as true diseases caused by abnormal regulation mechanisms. In other cases, the regulatory mechanisms are normal, but the emotional response still is not useful. This situation may exist because our modern environment is different from the environment in which we evolved, or because an idiosyncratic learning history has resulted in maladaptive patterns (Gilbert 1989; Hoop, personal communication 1989; Nesse 1984; Weinrich 1980; Wenegrat 1990). An evolutionary view suggests the division of emotional problems into three kinds: (a) those that result from a defect in the underlying mechanisms, (b) those in which the mechanisms are normal but the emotion they produce is maladaptive, and (c) those in which the emotion is normal and useful, even though it is painful.

For want of a functional analysis of emotions, a whole class of mental disorders has been underemphasized, namely, conditions in which the normal capacity for a painful emotion is absent. People do not complain about the lack of ability to experience fear, guilt, boredom, pride, or envy, but the absence of these capacities must, nonetheless, cause dysfunction/ even if it does not cause dissatisfaction.

Genetic contributions to a disorder do not necessarily mean that it results from a defect in underlying mechanisms. Genetic tendencies to strong or weak experience of a particular emotional response vary from person to person, just as a tendency to vomit more or less easily will vary. People who vomit with relatively little provocation do not have a 
genetic disease, nor do people who experience anxiety with little provocation. Furthermore, the association of physiological abnormalities with an emotional state does not imply that the state is caused by a defect or even by the physiological changes, except in the trivial sense that such changes must mediate every process in the brain.

Implications for Anxiety Research

An evolutionary view of emotions has implications for all areas of psychiatry, but I will comment only on the area I know best, research on the anxiety disorders.

Diagnostic criteria for the subtypes of anxiety have sometimes been sought as if the subtypes were different diseases with different etiologies. This assumption has led to much effort to arrive at definitive criteria for various anxiety disorders. If the subtypes of anxiety are viewed as correlates of different kinds of danger, the problem of finding diagnostic criteria for anxiety disorders is approached differently. Although each subtype of anxiety is expected to have its own attributes, substantial overlap of phenomenology is expected because the responses to one kind of threat often are also appropriate responses to other threats. Furthermore, cues for one kind of threat often indicate the possible presence of another threat and thus should elicit other kinds of anxiety to some degree. In sum, an evolutionary approach suggests that anxiety syndromes be approached as prototypical constellations that are expressed to various degrees, instead of categorical entities with specific and distinct etiologies.

The anxiety disorders are not gross malfunctions akin to epilepsy; they are only overly responsive defenses, much more like a tendency to vomit easily. Clarification of this distinction between those manifestations of disease that result from defensive operations and those that result from defects in the organism is a useful contribution of an evolutionary perspective to medicine in general (Williams and Nesse 1990). Its application to anxiety disorders would de-emphasize efforts to delineate the brain mechanisms that mediate anxiety and increase efforts to understand the mechanisms, cognitive and physiological, that regulate anxiety.

Finally, the abuse potential of anxiety-relieving drugs must be considered. As we gain increasing power to block anxiety and other aversive but normal emotions, we will rapidly confront the gaps in our understanding of the functions of the emotions. Today, most of the reasons given for not abusing drugs are based on medical or psychological complications. An evolutionary approach suggests that any drug 
that blocks normal emotional capacities will tend to decrease fitness. The common intuition that there is always a price for using drugs to feel better is supported by an evolutionary view of the emotions.

The Principle of Defensive Overresponsiveness

These conclusions are bleak. Must we set aside our new powers to relieve suffering because they often block useful responses? The answer depends on how natural selection has shaped the mechanisms that regulate defensive responses. Whether the defense is pain, nausea, or fear, the regulatory mechanism must assess the presence of the threat and express the protective response to the correct degree. The cost of a false alarm is relatively small-usually some wasted time and a few calories. The cost of not expressing a defensive response in the presence of a threat may, however, be huge. A game theory analysis of such tradeoffs concludes that maximum benefit results when the costs of false positive errors equals the costs of false negative errors. As a result, natural selection shapes regulatory systems for defensive responses that inevitably seem substantially overresponsive. Defensive responses often seem too quick, too intense, and too prolonged. Much of the time they are, in fact, more intense than is essential. This explains how it can be that physicians often relieve nausea, fever, pain, diarrhea, and anxiety without dire complications. And this is one reason for hope that a better understanding of the evolutionary functions of the emotions will enable us to decrease our normal, but unnecessary, emotional suffering.

\section{CONCLUSION}

The broad conclusions, that the emotions are useful and that they have been shaped by natural selection, are less and less controversial. The crucial issue now, in my opinion, is to decide how best to formulate explicit evolutionary explanations of emotions. I advocate an adaptationist approach in which emotions, like other traits, are explained in terms of the adaptive functions by which they increase Darwinian fitness. However, the functions of emotions cannot be formulated as readily as can those of other traits. Although a turtle's shell can be explained by the selective force of predation, love and anger do not correspond as simply to specific selective forces. For this reason, I argue that emotions are best viewed as specialized states of operation that give advantages in particular situations; it is the adaptive challenges of these 
situations that are the selective forces to which the details of an emotional state correspond.

The three illustrative groups of emotions each support this thesis in a different way. The excellent fit between the subtypes of fear and the different kinds of threats supports the general prediction that emotions correspond to situations. The physiological, cognitive, and behavioral changes associated with anxiety support the prediction that the details of an emotional state can usefully be considered aspects of design that correspond to the requirements of the situation.

Happiness and sadness illustrate the more basic expectation that observed capacities for emotional states must correspond to some situation in which they offer an advantage, even if the variables that define the situation are hard to discern. The characteristics of happiness and sadness suggest that they may be states specialized, respectively, for propitious and unpropitious circumstances.

The social emotions correspond well to the adaptively challenging situations that arise in reciprocity relationships, and the characteristics of these emotions can be understood as adaptations to those challenges. Of particular interest is the possibility that the very "irrationality" of these emotions may be essential to their adaptive functions. Love, anger, guilt, and anxiety can achieve their purposes only if they cannot easily be overridden by cognition. This conclusion challenges a central assumption of much modern psychological treatment. Insight into one's real motives, and actions based on rational considerations, are not always useful. In fact, if distortions and self-deceptions are useful to normal relationships, there may be complications if they are disrupted.

Clinicians must currently try to understand and treat emotional disorders without the benefit of a reliable theory of normal emotions. As a theory emerges, its practical importance will quickly be recognized. Even at this early stage, several implications may prove helpful. The first is that we have bad feelings for good reasons. Fear, anger, sadness, and loneliness are not abnormal, they are defenses that help us to deal with situations that decrease fitness. In order to explain them, we should look first not to brain mechanisms or personality characteristics, but to the current life situation of the person experiencing this feeling. What resources are being deployed using what strategies to attain what goals? What is the outlook for the future of this person's ability to achieve his or her goals by these means? These questions are the essential core of an evaluation for a possible emotional disorder. An outline for an evolutionary psychobiological life-situation analysis is proving enormously helpful to me in understanding the origins of my patients' difficulties.

The dilemmas posed by the new availability of psychotropic drugs and psychological treatments may also be clarified by an evolutionary 
approach to emotions. The general conclusion-that adaptation is disrupted by any interference with normal emotional capacities-is tempered by recognition that natural selection has shaped overly sensitive defensive reactions. Some mental suffering that is normal may, nonetheless, be unnecessary. But before we can know what kinds of suffering can or cannot be relieved without unduly compromising adaptation, we will need a much deeper understanding of the evolutionary functions of the emotions.

This work was supported by the University of Michigan Evolution and Human Behavior Program and by the Psychiatry and Evolutionary Psychobiology Project. The participants in a seminar I taught with Barbara Smuts provided the original impetus for this work, and participants in the Psychiatry and Evolutionary Psychobiology Study Group offered critiques, especially Darwin K. Hoop, whose detailed comments were essential to the final manuscript. Barbara Polcyn provided invaluable secretarial and editorial help.

Randolph M. Nesse, Associate Professor of Psychiatry at the University of Michigan, is Associate Director of the Anxiety Disorders Program and Director of the Psychiatry and Evolutionary Psychobiology Project. He is a member of the University of Michigan Evolution and Human Behavior Program and has helped to organize the Human Behavior and Evolution Society.

\section{REFERENCES}

Ainsworth, M. D., M. C. Blehar, E. Waters, and S. Wall

1978 Patterns of Attachment: A Psychological Study of the Strange Situation. Hillsdale, New Jersey: Lawrence Erlbaum Associates.

Alexander, R. D.

1989 Evolution of the Human Psyche. In The Human Revolution, P. Mellars and

C. Stringer, eds. Pp. 455-513. Edinburgh: University of Edinburgh Press.

American Psychiatric Association

1987 Diagnostic and Statistical Manual of Mental Disorders, third ed., revised.

Washington, DC: American Psychiatric Association.

Arnold, M. B.

1960 Psychological Aspects. Emotion and Personality, vol. I. New York: Columbia

University Press.

Axelrod, R., and W. Hamilton

1981 The Evolution of Cooperation. Science 211:1390-1396.

Averill, J. R.

1980 On the Poverty of Positive Emotions. In Assessment and Modification of

Emotional Behavior, K. R. Blankstein, P. Pliner, and J. Polivy, eds. Pp. 7-46.

New York: Plenum Press.

Barkow, J.

1980 Biological Evolution of Culturally Patterned Behavior. In The Evolution of 
Human Social Behavior, J. S. Lockard and D. C. Paulbus, eds. Pp. 277-296.

Engelwood Cliffs, New Jersey: Prentice-Hall.

Bowlby, J.

1973 Separation: Anxiety and Anger. Attachment and Loss, voL 2. New York: Basic Books.

Cannon, W. B.

1929 Bodily Changes in Pain, Hunger, Fear and Rage. New York: Harper.

Cosmides, L., and J. Tooby

1989 Evolutionary Psychology and the Generation of Culture, Part II. Case

Study: A Computational Theory of Social Exchange. Ethology and Sociobiology 10:51-98.

Curio, E.

1978 Cultural Transmission of Enemy Recognition. Science 202:899-901.

Daly, M., M. Wilson, and S. J. Weghorst

1985 Male Sexual Jealousy. Ethology and Sociobiology 3:11-27.

Darwin, C.

1965 Expression of Emotions in Man and Animals. Chicago: University of Chicago

Press. [originally published in 1872.]

Dawkins, R.

1982 The Extended Phenotype. San Francisco: W. H. Freeman.

Duffy, E.

1941 An Explanation of "Emotional" Phenomena without the Use of the Concept "Emotion." Journal of General Psychiatry 25:283-293.

Eibl-Eibesfeldt, I.

1980 Strategies of Social Interaction. In Theories of Emotion. Emotion: Theory,

Research, and Experience, vol. I, R. Plutchik and H. KelIerman, eds. Pp.

57-80. New York: Academic Press.

Ekman, P., ed.

1982 Emotion in the Human Face, second ed. Cambridge: Cambridge University Press.

Emde, R. N., and T. Gaensbauer

1981 Some Emerging Models of Emotion in Human Infancy. In Behavioral

Development, I. Immelmann, G. W. Barlow, L. Petrinovich, and M. Main, eds. Pp. 568-588. Cambridge: Cambridge University Press.

Frank, R. H.

1988 Passions within Reason: The Strategic Role of the Emotions. New York: W. W.

Norton.

Gardner, R, Jr.

1982 Mechanisms in Manic-Depressive Disorder. Archives of General Psychiatry 39:1436-1441.

Gaylin, W.

1979 Feelings: Our Vital Signs. New York: Ballantine Books.

Gilbert, P.

1989 Human Nature and Suffering. Hillsdale, New Jersey: Lawrence Erlbaum

Associates.

Hamburg, D. A.

1968 Emotions in the Perspective of Human Evolution. In Perspective on Human 
Evolution, vol. I, S. L. Washburn and P. C. Jay, eds. Pp. 246-257. New York: Holt, Rinehart \& Winston.

Hamilton, W.

1964 The Genetical Evolution of Social Behavior. Journal of Theoretical Biology 7:1-52.

Harlow, H. F., and R. R. Zimmerman

1959 Affectional Responses in the Infant Monkey. Science 130:421-423.

Hartung, J.

1988 Deceiving Down. In Self-Deception: An Adaptive Mechanism, J. S. Lockard and D. L. Paulhus, eds. Pp. 120-185. Engelwood Cliffs, New Jersey: Prentice-Hall.

Hinde, R. A.

1972 Concepts of Emotion. In Physiology, Emotion, and Psychosomatic Illness.

Ciba Foundation Symposium No.8. Amsterdam: Associated Medical Publishing.

Izard, C. E.

1977 Human Emotions. New York: Plenum.

Izard, C. E., J. Kagan, and R. B. Zajonc

1984 Introduction. In Emotions, Cognition, and Behavior, C. E. Izard, J. Kagan, and R. B. Zajonc, eds. Pp. 1-14. Cambridge: Cambridge University Press. James, W.

1962 Psychology: A Brief Course. In The Emotions. Pp. 375-391. New York: Collier Books. [originally published in 1880.]

Konner, M.

1982 The Tangled Wing. New York: Holt, Rinehart \& Winston.

Lazarus, R. S., A. D. Konner, and S. Folkman

1980 Emotions: A Cognitive-Phenoneurological Analysis. In Theories of Emotion. Emotion: Theory, Research, and Experience, vol. I, R. Plutchik and H. Kellerman, eds. Pp. 189-215. New York: Academic Press.

Leeper, R. W.

1948 A Motivational Theory of Emotions to Replace "Emotions As a Disorganized Response." Psychology Review 55:5-21.

Lelliott, P., I. Marks, G. McNamee, and A. Tobena

1989 Onset of Panic with Agoraphobia. Archives of General Psychiatry 46:10001004.

Livesey, P. J.

1986 Learning and Emotion: A Biological Synthesis. Hillsdale, New Jersey: Lawrence Erlbaum Associates.

Lutz, K.

1982 The Domain of Emotion Words on Ifaluk. American Ethnologist 9:113-128.

Lyons, W.

1980 Emotion. Cambridge: Cambridge University Press.

Marks, I. M.

1987 Fears, Phobias and Rituals. New York: Oxford University Press.

Mayr, E.

1988 Towards a New Philosophy of Biology. Cambridge: Belknap Press of the Harvard University Press. 
McGuire, M. T., and A. Troisi

1987 Physiological Regulation-Deregulation and Psychiatric Disorders. Ethology and Sociobiology 8:9s--255.

Mineka, S., R. Keiv, and V. Price

1980 Fear of Snakes in Wild and Laboratory-Reared Rhesus Monkeys (Macaca mulatta). Animal Learning and Behavior 8:653-663.

Nadelmann, E. A.

1989 Drug Prohibition in the United States: Costs, Consequences, and Alternatives. Science 245:939-946.

Nesse, R. M.

1984 An Evolutionary Perspective on Psychiatry. Comparative Psychiatry 25: 575-580.

1988 Panic Disorder: An Evolutionary View. Psychiatric Annals 18(8):478-483. 1990 The Evolution of Repression and the Ego Defenses. Submitted to Journal of the American Academy of Psychoanalysis.

Nesse, R. M., and A. T. Lloyd

1990 The Evolution of Psychodynamic Mechanisms. In The Adapted Mind: Evolutionary Psychology and the Generation of Culture, J. Barkow, L. Cosmides, and J. Tooby, eds. New York: Oxford University Press.

Ohman, A.

1987 The Psychophysiology of Emotion: An Evolutionary Cognition Perspective. Advances in Psychophysiology 2:79-127.

Ohman, A., U. Dimberg, and L. Ost

1985 Animal and Social Phobias: Biological Constraints on Learned Fear Responses. In Theoretical Issues in Behavior Therapy, S. Reiss and R. R. Brafzin, eds. Pp. 123-175. Orlando: Academic Press.

Panksepp, J.

1982 Toward a General Psychobiological Theory of Emotions. Behavioral Brain Sciences 5:407-467.

Plutchik, R. 1980 Emotion: A Psychoevolutionary Synthesis. New York: Harper and Row.

Plutchik, R., and H. Kellerman, eds.

1980 Theories of Emotion. Emotion: Theory, Research, and Experience, vol. 1. New York: Academic Press.

Price, J.5., and L. 510man

1987 Depression as Yielding Behavior. Ethology and Sociobiology 8:85s--985.

Schwartz, J. C., P. Shaver, and D. Kirson

1987 Emotion Knowledge: Further Exploration of a Prototype Approach. Journal of Personality and Social Psychology 52:1061-1086.

Scott, J. P.

1980 The Function of Emotions in Behavioral Systems: A Systems Theory Analysis. In Theories of Emotion. Emotion: Theory, Research, and Experience, vol. I, R. Plutchikand H. Kellerman, eds. Pp. 35-56. New York: Academic Press. Smuts, B. B.

1985 Sex and Friendship in Baboons. New York: Aldine. 
Staddon, J. E. R.

1983 Adaptive Behavior and Learning. Cambridge: Cambridge University Press.

Strongman, K. T.

1987 The Psychology of Emotion. New York: Wiley Press.

Thayer, R. E.

1989 The Biopsychology of Mood and Arousal. Oxford: Oxford University Press.

Tinbergen, M.

1963 On the Aims and Methods of Ethology. Zeitschrift Tierpsychologie 20: 410-433.

Tomkins, 5.5 .

1980 Affect as Amplification: Some Modifications in Theory. In Theories of Emotion. Emotion: Theory, Research, and Experience, vol. I, R. Plutchik and H. Kellerman, eds. Pp. 141-164. New York: Academic Press.

Trivers, R. L.

1971 The Evolution of Reciprocal Altruism. Quarterly Review of Biology 46: 35-57.

1981 Sociobiology and Politics. In Sociobiology and Politics, E. White, ed. Pp. 1-43. Lexington: Lexington Books.

Weinrich, J. D.

1980 Toward a Sociobiological Theory of the Emotions. In Theories of Emotion. Emotion: Theory, Research, and Experience, vol. I, R. Plutchik and H. Kellerman, eds. Pp. 113-138. New York: Academic Press.

Wenegrat, B.

1990 Sociobiological Psychiatry: A New Conceptual Framework. Menlo Park, California: Addison-Wesley.

Williams, G. C.

1966 Adaptation and Natural Selection: A Critique of Some Current Evolutionary Thought. Princeton: Princeton University Press.

Williams, G. C., and R. M. Nesse

1990 The Dawn of Darwinian Medicine. Submitted to Quarterly Review of Biology.

Wilson, E. O.

1975 Sociobiology. Boston: Belknap Press of the Harvard University Press.

Young, J. Z.

1979 Programs of the Brain. Oxford: Oxford University Press.

Zahavi, A.

1976 The Testing of a Bond. Animal Behavior 25:246-247. 